\title{
Comment on Checa MA et al. J Assist Reprod Genet DOI 10.1007/s10815-009-9328-4
}

\author{
Ernest H. Y. Ng
}

Received: 13 October 2009 / Accepted: 23 November 2009/Published online: 30 December 2009

(C) Springer Science+Business Media, LLC 2009

I read with interest the recent review paper by Checa et al. [1]. Preimplantation genetic screening for aneuploidy is now widely used in many IVF programs in order to improve the success rate of subfertile patients who have poor prognosis related to advanced maternal age [2]. The first review by Twisk et al. [3] was first published in 2006 and there are seven randomized trials published between 2007 and 2008. Therefore, this review and meta-analysis in this area is timely.

The selection of appropriate randomized trials in the meta-analysis is of utmost importance and it is important to avoid duplication of trials. It appears that the study of Schoolcraft et al. [4] is a full paper version of the abstract by Stevens et al. [5], although I could not find any mention of the abstract by Stevens et al. [5] in the full paper. The investigators were from the same institution and the studies were carried out during the same period: from May 2002 to March 2004.

I wonder if this information has been sought from these investigators to clarify the above point. Although the deletion of the abstract by Stevens et al. [5] in the meta-analysis is unlikely to change the overall results, it is still important to follow the basic principles of the meta-analysis.

\section{References}

1. Checa MA, Alonso-Coello P, Solà I, Robles A, Carreras R, Balasch J. IVF/ICSI with or without preimplantation genetic screening for aneuploidy in couples without genetic disorders: a systematic review and meta-analysis. J Assist Reprod Genet. 2009;26:273-83.

2. Goossens V, Harton G, Moutou C, Traeger-Synodinos J, Van Rij M, Harper JC. ESHRE PGD Consortium data collection IX: cycles from January to December 2006 with pregnancy follow-up to October 2007. Hum Reprod. 2009;24:1786-810.

3. Twisk M., Mastenbroek S., van Wely M., Heineman MJ., Van der Veen F., Repping S. Preimplantation genetic screening for abnormal number of chromosomes (aneuploidies) in in vitro fertilisation or intracytoplasmic sperm injection. Cochrane Database Syst Rev. 2006;(1):CD005291.

4. Schoolcraft WB, Katz-Jaffe MG, Stevens J, Rawlins M, Munne S. Preimplantation aneuploidy testing for infertile patients of advanced maternal age: a randomized prospective trial. Fertil Steril. 2009;92:157-62.

5. Stevens J, Wale P, Surrey ES, Schoolcraft WB. Is aneuploidy screening for patients aged 35 or over beneficial? A prospective randomized trial. Fertil Steril. 2004;82(Suppl 2):249. [Abstract].

\section{E. H. Y. $\mathrm{Ng}(\square)$}

Department of Obstetrics and Gynaecology,

The University of Hong Kong,

Hong Kong, Hong Kong

e-mail: nghye@hkucc.hku.hk 